ORIGINAL ARTICLES

\title{
Drug related medical emergencies in the elderly: role of adverse drug reactions and non-compliance
}

\author{
S Malhotra, R S Karan, P Pandhi, S Jain
}

\begin{abstract}
Background-Adverse drug reactions and non-compliance are important causes of admissions in the elderly to medical clinics. The contribution of adverse drug reactions and non-compliance to admission by the medical emergency department was analysed.

Methods-A total of 578 consecutive elderly patients admitted to the medical emergency department were interviewed to determine the percentage of admissions due to adverse drug reactions or noncompliance with medication regimens, their causes, consequences, and predictors.

Results-Eighty three (14.4\%) of the 578 admissions were drug related: $39(6.7 \%)$ caused by adverse drug reactions and 44 $(7.6 \%)$ caused by non-compliance with medication. One hundred ninety two (33.2\%) patients had a history of noncompliance. Factors associated with an increased risk of admission because of an adverse drug reaction were patients with diabetes or neoplasms, and patients using numerous different medications. Factors associated with a higher risk of hospitalisation because of non-compliance were poor recall of the medication regimen, seeing numerous physicians, female sex, polypharmacy, drug costs, and switching over to non-conventional forms of treatment.
\end{abstract}

Conclusion-Many elderly admissions are drug related, with non-compliance accounting for a substantial fraction of these. Elderly people at high risk of suffering a drug related medical emergency are identified and suitable interventions may be planned by the healthcare policymakers to target them.

(Postgrad Med f 2001;77:703-707)

Keywords: adverse drug reactions; non-compliance; drug related medical emergencies; elderly

Of all the people who have ever lived to age 65, more than two thirds are currently alive. As individuals age, they are more likely to suffer from disease, disability, and drug side effects. ${ }^{1}$ Adverse drug reactions (ADRs) are an important cause of morbidity and hospital admissions among the elderly. ${ }^{2}$ In a large, multicentre study, adverse reactions were a contributing cause in $10.5 \%$ of consecutive geriatric admissions. ${ }^{3}$ Although some studies have shown that the incidence of ADRs may be as high as $25 \%$, a rate that is twofold or threefold higher than in younger patients, the notion that age is a critical predisposing determinant of adverse reactions is controversial. ${ }^{4}$ In fact, the incidence of ADRs increased with age in only five of 12 studies that evaluated age as a variable. ${ }^{4}$ However, elderly patients may have multiple disease states and may use a wide variety of drugs, increasing the potential for altered responsiveness to drugs and a higher incidence of adverse effects compared with younger patients. ${ }^{6}$ Moreover, a substantial proportion of the elderly are non-compliant; estimates vary from $26 \%$ to $59 \% .^{7-10}$ While several studies have attempted to identify characteristics that predict non-compliance, results have been contradictory. For example, one study found higher rates of non-compliance among elderly people who were over 75 years of age, living alone, less educated, and with more diagnoses ${ }^{10}$; another study found no significant differences using these same variables. ${ }^{8}$

The current study was designed specifically to address the drug taking behaviour of the elderly, taking into consideration variables such as living situation, cost of medications, and number of physicians seen regularly. Our objectives were to determine the proportion of medical emergency admissions that are secondary to ADRs or non-compliance and the causes and predictors of non-compliance and ADRs.

\section{Patients and methods}

The study was conducted in the medical emergency department of a 1200 bed tertiary care referral hospital in north India. All patients 65 years and over who were admitted to the department between January and July 2000 were included in the study. The total sample size was 578 .

All patients were interviewed, usually within 24 hours of admission. The methods followed have been described. ${ }^{11}$ Briefly, information obtained included the patient's age, sex, assistance in taking their medications, number of physicians seen on a regular basis, medications taken on admission, history of noncompliance, and reasons for non-compliance. Determining a patient's history of noncompliance was attempted in a nonjudgmental way. The question was asked as 
follows: "Many patients that are taking different medications over long periods of time will occasionally not take one or more of their medications. Were you able to take all the medications regularly? Do you ever take more or less of the amount prescribed for any reason?".

Medical records were used to obtain diagnosis at admission, drug history, and to corroborate information provided by patients during the interview. Patients' knowledge of their medication regimen was determined by asking them to recite their regimen and comparing this response with information in their medical records. Whenever possible, family members were consulted for further corroboration. For confused or unresponsive patients, the required information was obtained from family members.

Each patient in the study was evaluated by one of us to determine if the admission was drug related, whether non-compliance or an ADR was a causative factor in each admission, and what drug(s) was (were) implicated. The strength of the casual relationship was also assessed, whether ADR or non-compliance was a definite, probable, possible, or contributing factor in that admission.

During the course of the study, 47 patients died or were discharged before they could be interviewed, two were either uncommunicative or too confused to be interviewed, with no family members available; this left a total study group of 578 admissions. The $\chi^{2}$ test and two tailed Fisher's exact test were used to determine if there were statistically significant differences between proportions.

\section{DEFINITIONS}

The definitions used in this study, as described in similar studies, were:

Adverse drug reaction - Any response that is noxious and unintended and that occurs at doses normally used in man for prophylaxis, diagnosis, or treatment, excluding a failure to accomplish the intended purpose. ${ }^{12}$

Drug related hospital admission-Admission caused by any undesirable clinical manifestation that is consequent to and caused by the administration of a particular drug. The clinical manifestation may be a clinical sign, symptom, or abnormal laboratory test or it may be a cluster of abnormal signs, symptoms, or tests. ${ }^{113}$

Drug non-compliance-The extent to which the patient's drug taking behaviour (in terms of taking medication) coincides with the prescription. ${ }^{14}$

Definitions used in assessing causality were (1) definite or probable: the reaction commonly known to occur, with clear cut temporal association or laboratory confirmation; signs and symptoms were improved by dose adjustment, stopping or reinstating the drug; the signs and symptoms could not reasonably be explained by the known characteristics of the patients clinical condition or by the effects of other drugs; (2) possible: reaction known to occur with less clear cut temporal relationship;
Table 1 Characteristics of the study population

\begin{tabular}{ll}
\hline Mean (SD) age, years & $72.5(4.7)$ \\
Living alone, \% & 13.6 \\
Completed high school, \% & 32.7 \\
Average number of different medications & 4.1 \\
$\quad$ prescribed & \\
Average number of pills taken per day† & 5.9 \\
Average monthly cost of medications & $\$ 4.3$
\end{tabular}

*Including medications taken as needed.

†Including only medications prescribed by physician.

other causes also possible; the signs and symptoms were improved by dose adjustment, stopping, or reinstitution of the drug therapy; (3) contributing factor: there is a definite or probable link between drug treatment and admitting diagnosis; however, there are other complications that are unrelated to drug treatment, which are also a cause of admission.

\section{Results}

The mean age of the study groups was 72.5 years, ranging from 65 to 91 years. The mean age for men was 71.6 years and for women 73.2 years. There was a slight preponderance of females $(52.9 \%)$. More than $10 \%$ of the elderly were living alone and about one fourth completed high school. On average, these patients were taking between five and six medications a day and had four to five different medications prescribed (table 1). Eighty three $(14.4 \%)$ of the 578 admissions to the medical emergency department were judged to be drug related: 39 admissions $(6.7 \%)$ were caused by ADRs and $44(7.6 \%)$ were related to medication non-compliance. Of 83 admissions, the causal relationship was considered to be definite or probable in 23 , possible in 44 , and a contributing factor in 16 . The total hospital cost of all drug related admissions in the department was US $\$ 3775$ ( 1 US $\$=46$ Indian rupees); $\$ 1471$ for admissions related to ADRs and $\$ 2304$ for admissions related to non-compliance.

Among the 39 admissions related to ADRs, hypoglycaemia induced by oral hypoglycaemic agents was the commonest $(30.8 \%)$. Other drugs most commonly implicated were nonsteroidal anti-inflammatory drugs (NSAIDs) and anticancer drugs (table 2). There was no sex related difference in ADR related admissions. The greater the number of different medications prescribed, the greater the cost of admissions related to ADRs $(\mathrm{p}<0.01)$ (table 3$)$.

Table 2 Medications (or therapeutic groups) implicated in emergency admissions related to ADRs

\begin{tabular}{ll}
\hline Medication (or therapeutic groups) & $\begin{array}{l}\text { No of times } \\
\text { cited }\end{array}$ \\
\hline Oral hypoglycaemics & 12 \\
NSAIDs† & 6 \\
Cancer chemotherapy $\ddagger$ & 5 \\
Antitubercular drugs\$ & 5 \\
Penicillins $\uparrow$ & 2 \\
Digoxin & 2 \\
Phenytoin & 2 \\
Others & 5
\end{tabular}

${ }^{\star}$ Includes glibenclamide (8), gliclazide (3), and glipizide (1). †Includes indomethacin (4), aspirin (2).

łIncludes cyclophosphamide (2), methotrexate (2), 5-fluorouracil (1)

§Includes isoniazid and rifampicin combination.

IIncludes crystalline penicillin and ampicillin. 
Table 3 Proportion of patients admitted with ADRs

\begin{tabular}{lcl}
\hline Characteristic & $\begin{array}{l}\text { No of patients } \\
\text { interviewed }\end{array}$ & $\begin{array}{l}\text { No (\%) of admissions } \\
\text { for ADRs }\end{array}$ \\
\hline No of different prescribed medications & \\
0 & 41 & $2(4.9)$ \\
$1-3$ & 355 & $15(4.2)$ \\
$4-10$ & 166 & $16(9.6)$ \\
11 or more & 16 & $6(37.6)$ \\
Monthly cost of treatment & \\
$\$ 0-4$ & 431 & $17(3.9)$ \\
$\$ 5-10$ & 104 & $12(11.5)$ \\
$>\$ 10$ & 43 & $10(23.2)$
\end{tabular}

^Not including medications taken as needed.

†Cost in US dollars, $\$ 1=46$ Indian rupees (approximately).

The proportion of patients whose admission was related to an ADR also varied with the monthly cost of medication: about one fourth of patients paying $\$ 10$ or more per month had an ADR compared with $5.2 \%$ for those paying less than this amount $(\mathrm{p}<0.05)$. When controlling for the number of different medications, ADRs were 2.4 times more prevalent among those paying over $\$ 5$ a month on medications (95\% confidence interval 1.1 to 6.3 ) and 3.7 times more prevalent among those paying over $\$ 10$ a month (95\% confidence interval 1.3 to 12.7).

Stepwise logistic regression analysis found the following variables to be associated with admissions due to ADRs: the number of different prescription medications used, the number of physicians seen regularly, and patients living alone. The greater the number of different prescriptions drugs taken, the greater the risk of emergency admission related to an ADR - the odds ratio for those taking three or more different medications compared with those taking less than three was 4.3. Patients who were regularly seeing more than three physicians were at higher risk of presenting to the medical emergency compared with those seeing three or less (odds ratio 5.7). Patients who were living alone were more likely to attend medical emergency because of an ADR as compared to those living with families (odds ratio 4.3).

\section{NON-COMPLIANCE}

Among the study group, 192 (33.2\%) reported a history of non-compliance within the past year. The most common form of noncompliance was underuse, accounting for $71 \%$ of all non-compliance, followed by overuse $(17 \%)$ and misuse $(2 \%)$. Sixty three per cent of all non-compliance was reported as being intentional and $37 \%$ reported as being unintentional.

Table 4 Main causes of medication non-compliance

\begin{tabular}{lll}
\hline Stated causes & $\begin{array}{l}\text { No (\%) with past history } \\
\text { of non-compliance }\end{array}$ & $\begin{array}{l}\text { No (\%) with current admission } \\
\text { related to non-compliance }\end{array}$ \\
\hline Cost & $53(27.6)$ & $16(36.4)$ \\
Inadequate instruction & $18(9.4)$ & $11(25.0)$ \\
Switch to unconventional prescription & $23(12.0)$ & $10(22.7)$ \\
Side effects & $38(20.0)$ & $5(11.4)$ \\
Forgetfulness & $41(21.3)$ & $3(6.8)$ \\
Perceived as not necessary & $15(7.8)$ & $3(6.8)$ \\
Dislikes taking medicines & $7(3.6)$ & $3(6.8)$ \\
Others & $9(4.7)$ & 0 \\
Total & 192 & 44 \\
\hline
\end{tabular}

^Some respondents gave more than one response.
Table 5 Drug groups and drugs implicated in hospitalisations due to non-compliance

\begin{tabular}{ll}
\hline Medication & No of times cited \\
\hline Antihypertensives & 24 \\
Enalapril & 8 \\
Amlodipine & 8 \\
Atenolol & 2 \\
Others & 6 \\
Antiasthmatics & 8 \\
Theophylline & 3 \\
Steroids & 3 \\
$\beta_{2}$-agonists & 2 \\
Antidiabetics & 5 \\
Insulin & 4 \\
Glibenclamide & 1 \\
Anticonvulsants & 4 \\
Phenyoin & 3 \\
Valproate & 1 \\
Antianginals & 3 \\
Isosorbide dinitrate & 2 \\
Nitroglycerin & 1 \\
\hline
\end{tabular}

The most common cause of non-compliance among patients with a history of noncompliance was cost $(27.6 \%$ of respondents) followed by forgetfulness $(21.3 \%)$, side effects $(20.0 \%)$, and patients switching to unconventional forms of treatment $(12.0 \%)$ (table 4 ). Among patients whose current admission was related to non-compliance, cost was again the most common cause $(36.5 \%)$ followed by inadequate instruction $(25.4 \%)$ and switch to non-conventional treatment $(22.7 \%)$. The drug classes most commonly implicated in hospitalisation due to non-compliance were antihypertensives and antiasthmatics (table 5).

The proportion of patients with a history of non-compliance was highest among cardiac admissions $(51.7 \%)$, followed by respiratory diseases (43.5\%), metabolic abnormalities $(26.4 \%)$, and central nervous system complaints $(19.7 \%)$. In contrast, among patients whose present admission was related to noncompliance, including only definite/probable and contributing factors as causative factors, the highest proportion was seen among those with cardiovascular diseases $(15.3 \%)$, followed by respiratory diseases $(7.4 \%)$, metabolic disturbances $(6.9 \%)$, and central nervous system disorders $(3.3 \%)$.

Several characteristics were found to be associated with admissions related to noncompliance (table 6). Women accounted for a higher proportion of non-compliant admissions than did men $(8.5 \%$ v $6.6 \%, \mathrm{p}<0.05)$. Patients' ability to recall their medication regimen was found to be associated with the rate of non-compliant admissions-those patients who could not recall their regimen had a higher rate of non-compliant admissions than those who could $(9.2 \% v 3.6 \%)$, while those patients who could only partially recall their regimens had the highest rate of non-compliant admissions $(18.4 \%, \mathrm{p}<0.001)$. The greater the number of physicians seen regularly by the patients, the greater the proportion of noncompliant admissions $(p<0.01)$. The odds ratio for non-compliance admissions patients seeing more than three physicians regularly compared with those seeing fewer than three was 5.0. The greater the number of different medications prescribed, the greater the proportion of non-compliant admissions 
Table 6 Proportions of patients admitted in the medical emergency for non-compliance

\begin{tabular}{|c|c|c|c|}
\hline \multirow[b]{2}{*}{ Total } & \multirow{2}{*}{$\begin{array}{l}\text { No of patients } \\
\text { interviewed } \\
578\end{array}$} & \multicolumn{2}{|c|}{$\begin{array}{l}\text { No (\%) of non-compliant } \\
\text { admissions }\end{array}$} \\
\hline & & $44(7.6)$ & \\
\hline Male & 272 & $18(6.6)$ & \\
\hline Female & 306 & $26(8.5)$ & $\mathrm{p}<0.05$ \\
\hline \multicolumn{4}{|l|}{ Recall of medication regimen } \\
\hline Patient recalls regimen & 334 & $12(3.6)$ & \\
\hline Patients cannot recall regimen & 141 & $13(9.2)$ & \\
\hline Patients with only partial recall of regimen & 103 & $19(18.4)$ & $\mathrm{p}<0.01$ \\
\hline \multicolumn{4}{|l|}{ No of physicians seen regularly } \\
\hline $0-1$ & 427 & $14(3.3)$ & \\
\hline $2-3$ & 106 & $17(16.0)$ & \\
\hline$>3$ & 45 & $13(28.9)$ & $\mathrm{p}<0.01$ \\
\hline \multicolumn{4}{|l|}{ No of different prescribed medications } \\
\hline $0-1$ & 41 & 0 & \\
\hline $1-2$ & 31 & $12(3.8)$ & \\
\hline$\geqslant 3$ & 220 & $32(14.5)$ & $\mathrm{p}<0.01$ \\
\hline
\end{tabular}

$(p<0.01)$. The odds ratio for those taking three or more different medications compared with those taking fewer than three was 4.3. The odds ratio for patients hospitalised for noncompliance with only partial recall for their medication regimen was 5.1 compared with those with total recall.

\section{Discussion}

Our study, which prospectively identified all drug related visits to a multidisciplinary medical emergency department showed that approximately $14 \%$ of all elderly admissions to the department were drug related. Only a few studies have analysed emergency department visits potentially related to the complications of drug therapy. ${ }^{15-18}$ Most of these studies included only ADRs, were focused on specialised hospital units, and patients of all age groups were included. Consequently, the proportion of admissions caused by drug related issues ranged from $2.3 \%$ to $27 \%$ and in a metaanalysis a weighted estimate of $5.1 \%$ of drug related admissions was derived. ${ }^{19}$

Sulfonylureas were responsible for hypoglycaemic reactions, this ADR is known to occur in $4 \%$ of patients, and is a particular problem in elderly. ${ }^{20}$ Severe acute gastritis, with or without gastric bleed, is a known complication of NSAID therapy, ${ }^{21}$ and NSAIDs have been identified as one of the areas of particular concern in others studies as well. ${ }^{15}$ Cancer chemotherapy was the other leading cause of ADR related emergency admission as in some other studies. ${ }^{11}$ Several factors may contribute to ADRs in the elderly. A progressive decline in many parameters of physiological function occurs with aging and may influence the disposition of drugs in geriatric patients. Impaired organ function, which may result from prior disease as well as from aging, alters drug kinetics, organ responses, and homoeostatic counter-regulation to drug effect. ${ }^{22}$

The direct relation between number of drugs prescribed and admissions due to ADR proves that the likelihood of toxicity increases as the number of drug prescribed rises. The independent association between ADRs and medication costs seen in our and some other studies could reflect the use of newer medications that are more costly. Those with higher medication costs could be using the more costly, recently introduced drugs for which there may be more side effects, more drug interactions, and, most importantly, less experience in the elderly, leading to incorrect dosage.

Our results also show that nearly $8 \%$ of all elderly admissions to the medical emergency department were related to non-compliance. This finding is comparable with what has been described in the literature $(2.9 \%, 7.4 \%$, and $10.5 \%),{ }^{23}$ even though other studies included all age groups, used differing definitions of non-compliance and considered medical (and not emergency) admissions. The percentage of hospitalised elders having a history of noncompliance $(33.2 \%)$ falls within the range of estimates produced by other studies $(25 \%$ to $50 \%)$. However, this may be an underestimate of the compliance as determination of a patient's history of non-compliance relies on self admission. There may an error in recall or the patient may be unwilling to disclose non-compliance. We used the interview method, which although problematic, has been validated as a practical and reasonably accurate means of determining whether a patient has been non-compliant. ${ }^{24-26}$

Cost was the frequently stated cause for non-compliance both in patients and with a history of non-compliance and those whose current hospitalisation was related to noncompliance. This is different to what has been reported in other studies where side effects and forgetfulness were the most common causes for non-compliance. ${ }^{11}{ }^{16-18}$ This may be due to the fact that many patients who visit our hospital have poor socioeconomic background and cannot afford medications. Inadequate instruction and patients switching over to nonconventional forms of therapy on their own were two important causes for non-compliance among patients whose admission was related to non-compliance. Ours being a tertiary care, referral hospital, many patients are referred by the registered medical practitioners or from peripheral hospitals where they may not be receiving proper instructions regarding use of medications. Moreover, most patients in our study were suffering from chronic illnesses, requiring life long treatment and because of illiteracy, poverty and misconceptions, started visiting providers of non-conventional therapies and may even stop conventional medications. This was an important reason for non-compliance and had not been reported in previous studies. While using the other stated reasons for non-compliance on which to base policy interventions is problematic, it is the last one (switching to unconventional forms of therapy), which may be targeted for intervention by the policymakers.

It is not surprising that more complicated medication regimens, an inability to properly recall the regimen, the greater number of physicians consulted regularly, and the greater number of preparations used were associated with increased risk of non-compliance and increased risk of a hospitalisation related to non-compliance. Moreover, patients with a partial recall of their medication regimen were at higher risk than those with no recall. It is difficult to explain but perhaps patients with no 
recall seek assistance more readily than those with partial recall.

The results of our study help identify several characteristics that can be used by health providers to identify elders at risk of suffering a drug related medical emergency. These include elderly diabetics; patients with neoplasms; patients on several medications concurrently with complicated regimens; patients who have only partial recall of their medication regimens; and those who are receiving expensive medications. Our results once again highlight the well known principle of geriatric clinical pharmacology: prescribe simpler regimens with fewer pills to be taken each day. Also, monitoring of prescriptions of the registered medical practitioners practising in the peripheral areas may help curtail drug related emergencies among the elderly. More importantly, our results suggest that better patient education about drug side effects and the pros and cons of unconventional therapies should help in decreasing noncompliance.

1 Resnick NM. Geriatric medicine. In: Tiernney LM, McPhee SJ, Papadakis MA, eds. Current medical diagnosi and treatment. 39th Ed. New York: Lange/McGraw-Hill, 2000: 47-70.

2 Beard K. Adverse reactions as a cause of hospital admission for the aged. Drugs Aging 1992;2:356-63.

3 Williamson J, Chopim JM. Adverse reactions to prescribed drugs in the elderly. A multicentric investigation. Age Ageing 1980;9:73-9.

4 Nolan L, O'Malley K. Prescribing for the elderly. Part I: sensitivity of the elderly to adverse drug reactions. $f \mathrm{Am}$ GeriatrSoc 1988;36:142-7.

5 Gurwitz GH, Avorn J. The ambiguous relation between aging and adverse drug reactions. Ann Intern Med 1991;39: 1093-8.

6 Montamat SC, Cusack BJ, Verstal RE. Management of drug therapy in the elderly. N Engl F Med 1989;321:303-9.

7 Stewart RB, Cluff LE. A review of medication errors and Stewart RB, Cluff LE. A review of medication errors and
compliance in ambulant patients. Clin Pharmacol Ther 1972; 13:463-8.

8 Cooper JK, Love DW, Raffoul PR. Intentional prescription nonadherence (noncompoiance) by the elderly. $\mathscr{f} \mathrm{Am}$ Geriat Soc 1982;30:329-33
9 German PS, Klein LE, McPhee SJ, et al. Knowledge of and compliance with drug regimens in the elderly. $f$ Am Geriatr Soc 1982;30:568-71.

10 Schwartz D, Wang M, Zeitz L, et al. Medication errors made by elderly, chronically ill patients. Am F Public Health 1962; 52:2018-29.

11 Col N, Fanwle JE, Krinholm P. The role of medication noncompliance and adverse drug reactions in hospitalization of the elderly. Arch Intern Med 1990;150:841-5.

12 Karch FE, Lasagna L. Adverse drug reactions. A critical review. FAMA 1975;12:1236-41.

13 McKenney JM, Harrison WL. Drug-related hospital admissions. Am F Hosp Pharm 1976;33:792-5.

14 Haynes RB, Taylor DW, Sackette DI, eds. Compliance in health care. Baltimore: Johns Hopkins University Press, 1979

15 Prince BS, Goetz CM, Rihn TL, et al. Drug-related emergency department visits and hospital admissions. $A m \mathcal{F}$ Hosp Pharm 1992;49:1696-700.

16 Scheneitman-Mclntire O, Farnea TA, Gordon N, et al. Medication misadventures resulting in emergency department visits at an HMO medical center. Am 7 Health Syst Pharm 1996;53:1416-22.

17 Llennehy CE, Kishi DT, Louic C. Drug-related illness in emergency department patients. Am f Health Syst Pharm 1996;1422-6.

18 Raschetti R, Morgutti M, Menniti-Ippolito F, et al. Suspected adverse drug events requiring emergency department visits or hospital admissions. Eur f Clin Pharmacol 1995;54:959-63.

19 Einarson TR. Drug-related hospital admissions. Ann Pharmacother 1993;27:832-40.

20 Pirce BJ, Peterson KR, Lawson DH. Undesired effects of sulfonylurea drugs. Adverse Drug Reactions and Acute Poisoning Reviews 1985;4:23-36.

21 Gabriel SE, Jaakimainen L, Bombarctier C. Risk for serious gastrointestinal complications related to use of nonsteroidal anti-inflammatory drugs. A meta-analysis. $N$ Engl $7 \mathrm{Med}$ 1991;115:787-96.

22 Cusack BJ, Nielson CP, Vestal RE. Geriatric clinical pharmacology and therapeutics. In: Speight TM, Holford NHG, eds. Avery's drug treatment. 4th Ed. Auckland: Adis International, 1997: 174-223.

23 Levy M, Mermelstein L, Hemo D. Medical admissions due to noncompliance with drug therapy. Int $\mathcal{f}$ Clin Pharmacol Ther Toxicol 1982;20:600-14.

24 Fletcher SW, Pappius EM, Harper SJ. Measurement of medication compliance in a clinical setting, comparison of three methods in patients prescribed digoxin. Arch Intern Med 1979;139:635-8.

25 Dudd P. In search of the gold standard for compliance measurement. Arch Intern Med 1979;139:627-8.

26 Haynes RB, Taylor DW, Sackett DL, et al. Can simple clinical measurements detect patient non-compliance? Hypertension 1980;2:757-64. 